\title{
EVALUATION OF THE PERIAPICAL HEALING FOLLOWING PULP REVASCULARIZATION USING INJECTABLE PRF VS NONSURGICAL ROOT CANAL TREATMENT IN MATURE PERMANENT TEETH WITH PERIAPICAL PERIODONTITIS. A CLINICAL STUDY
}

Lamiaa Ahmed Ibrahim*, Mohamed Nageh Tawfik** and Fatma M. Abu Naeem ${ }^{* * *}$

\begin{abstract}
Aim: The aim of the current study was to evaluate the effect of injectable platelet rich fibrin (i-PRF) revascularization technique VS conventional endodontic treatment on the periapical healing of mature permanent teeth with periapical periodontitis.

Materials and Methods: A total of 30 patients with apical periodontitis related to permanent central incisors were included in the study. The control group $(n=15)$ has undergone conventional root canal treatment using crown down technique on 2 visits with calcium hydroxide intracanal dressing in between visits and obturation was done using cold lateral compaction technique. The intervention group $(n=15)$ has undergone regenerative procedures. Regenerative protocol was carried out using $1.5 \%$ sodium hypochlorite irrigation and DAP intracanal medicament for 3 weeks. At the second visit, i-PRF was prepared and injected inside the root canal. The orifice was sealed with MTA followed by double sealing of the access by glass ionomer and composite-resin restoration. Clinical and radiographic evaluation was done for 1, 3,6, 9, and 12 months, and CBCT imaging was done after 12- month follow-up period.
\end{abstract}

Results: The i-PRF group recorded more decrease in the lesion size than the control group. However, the difference was not statistically significant yet, there was a highly significant statistical difference between the preoperative and postoperative measurements with great lesion size reduction within the i-PRF group

Conclusion: i-PRF revascularization is an effective treatment of apical periodontitis in permanent teeth with mature apex.

KEY WORDS: Regeneration, i-PRF, Mature teeth, Apical healing, Root canal treatment, Pulp revascularization.

* Associate Professor, Faculty of Dentistry Fayoum University

** Assistant Professor, Department of Endodontics Faculty of Dentistry Fayoum University Fayoum Governorate Egypt

*** Endodontic Department, Faculty of Dentistry, Cairo University, Egypt 


\section{INTRODUCTION}

Regenerative endodontics is a novel technique aiming at replacing damaged dentino-pulpal structures due to presence of deep caries or trauma that hinders the development of the root ${ }^{(1)}$. At the beginning, it was carried out with immature nonvital teeth to aid in root completion and apical closure unlike the apexification procedures or conventional root canal treatment which fail to promote dentin formation and hence continued root maturation the fact that makes the tooth more prone to fracture under masticatory loads. The first revascularization procedures were done using the conventional blood column concept generated by inducing bleeding from the periapical area through the root canal containing lots of undifferentiated stem cells and growth factors $(2,3,4)$. Then the regenerative protocol was modified by the introduction of the platelet rich plasma (PRP) and the platelet rich fibrin (PRF) which are totally autologous in nature, inexpensive and prepared with a very simple technique ${ }^{(5,6)}$. The results of these attempts were propitious and encouraging, showing favorable clinical outcomes and suggestive of periapical healing which encouraged us to use them on mature teeth with necrotic pulps ${ }^{(7,8)}$. Later on, worries concerning the incorporation of anticoagulants in PRP preparation that are known for inhibiting wound healing have been expressed. On the other hand, using of PRF in mature teeth with its gelatinous firm consistency may cause difficulty while introducing it into narrow mature canals. So, the creation of an innovative "injectable" form of PRF (i-PRF) has been proposed with aiming at providing endodontists with a simple technique utilizing the concentrate of platelets in a flowy form that can be applied either alone or in conjunction with other methods providing an adequate perspective for soft tissue as well as hard tissue healing owing to the genesis of a three-dimensional fibrin network into which the platelets, type I collagen, leukocytes, growth factors and osteocalcin, are embedded ${ }^{(9,10)}$. In the current study, innovative regenerative endodontic techniques were adopted making use of the (i-PRF) forming a scaffold as well as a source of growth factors to treat mature teeth with non-vital pulp and apical periodontitis.

\section{MATERIALS AND METHODS}

Thirty adults diagnosed with necrotic upper central incisor(s) were recruited from the diagnostic center of the Endodontic department clinic at the faculty of dentistry, Cairo University between the years 2018 and 2019. The study was performed in accordance with Helsinki declaration of the year 1975 for medical studies as revised in the year 2000. All the treatment procedures and the purpose of the work were explained for all the patients recruited for the study. The dental and medical history of all patients was thoroughly studied and medically compromised patients were excluded. All patients were asked to sign an informed consent that explained the aim of the study, and agreed to comply to a one year clinical and radiographic follow-up period where the assessment was carried out every 3 months.

The study inclusion criteria comprised healthy adults with an age range of 18-45 years old, with no sex predilection, diagnosed with pulp necrosis in mature maxillary central incisor(s) having a periapical radiolucency, negative response to both thermal (cold) and electric pulp testing, no tooth mobility, and a pocket depth less than $3 \mathrm{~mm}$, with or without pain on percussion. The history of the chief complaint was recorded including intensity, quality, onset, duration, location, course, and initiating and relieving factors of pain. The final diagnosis was pulp necrosis associated with apical periodontitis.

Radiographic examination was done with an indirect imaging system to detect the presence of periapical radiolucency, root morphology and curvature, to assure the absence of root calcifications and resorption. Cone beam computed tomography (CBCT) was performed preoperatively to detect the 
size, boundaries of the periapical lesion. To achieve radiometric standardization of the images, the same exposure parameters were set at the follow-up as follows, $90 \mathrm{KVP}, 8 \mathrm{Ma}, 6.1$ seconds exposure time, $125 \mu \mathrm{m}$ resolution, $5 \times 5 \mathrm{~cm}$ field of view (FOV), and image slice thickness $1.5 \mathrm{~mm}$.

For the control group, during the first visit, the teeth were anaesthetized by buccal infiltration technique using $1.8-3.6 \mathrm{ml}$ of $2 \%$ lidocaine with $1: 100,000$ epinephrine as a local anesthetic solution. A proper rubber dam isolation was done and an access cavity was performed, negotiation of the canals was done using stainless steel hand k- files size \# 15. An electronic apex locator was used for the working length determination, then its reading was confirmed with an intraoral periapical radiograph to be $0.5-1 \mathrm{~mm}$ shorter than radiographic apex. The chemo-mechanical preparation of the root canals was carried out employing the crown-down technique till reaching an apical canal preparation corresponding to K-file size \#60. The canals were thoroughly irrigated using $1.5 \%$ sodium hypochlorite using a plastic disposable syringe $(5 \mathrm{ml})$ with a 25 -gauge closed end side vented needle. The canals were dried with sterile paper points of the same size of the master apical file (MAF). Calcium hydroxide intracanal medicament was then injected into the canal. A dry cotton pellet was placed inside the access cavity which was temporarily sealed by glass ionomer cement. All the patients were recalled after 3 weeks for the second visit where completion of root canal treatment was done. The rubber dam was placed and the glass ionomer cement was removed. The root canals were irrigated with $20 \mathrm{ml}$ of $17 \%$ EDTA solution for 1 minute, followed by normal saline. Then the canals were dried using paper points and were obturated utilizing gutta-percha by the cold lateral compaction technique and an epoxy resin based root canal sealer. After obturation, the access cavity was cleaned from excess sealer with a cotton pellet soaked in alcohol and was sealed with a glass ionomer cement base and resin composite restoration.
For the intervention group, during the first visit, the same steps were done as that of the first visit of the control group where the teeth were anesthetized with the buccal infiltration technique using 1.8-3.6 mL 2\% lidocaine with 1:100,000 epinephrine as a local anesthetic solution. A proper rubber dam isolation was done and an access cavity was performed, negotiation of the canals was done using stainless steel hand $\mathrm{k}$ - files size \# 15. An electronic apex locator was used for the working length determination, then its reading was confirmed with an intraoral periapical radiograph to be $0.5-1 \mathrm{~mm}$ shorter than radiographic apex. The chemo-mechanical preparation of the root canals was carried out employing the crown-down technique till reaching an apical canal preparation corresponding to $\mathrm{K}$-file size \#60. The canals were thoroughly irrigated using $1.5 \%$ sodium hypochlorite using a plastic disposable syringe $(5 \mathrm{ml})$ with a 25 -gauge closed end side vented needle. The canals were dried with sterile paper points of the same size of the master apical file (MAF). Calcium hydroxide intracanal medicament was then injected into the canal. A dry cotton pellet was placed inside the access cavity which was temporarily sealed by glass ionomer cement. At the second visit (after 3 weeks from the first visit), a $1.8-\mathrm{mL}$ of $3 \%$ mepivacaine plain anesthetic was administered as a buccal infiltration. The rubber dam was placed, and the glass ionomer cement was removed. Reirrigation of root canals was done using $20 \mathrm{~mL}$ of $17 \%$ EDTA solution for 1 minute followed by saline irrigation ${ }^{(11,12)}$. A $10-\mathrm{mL}$ sample of whole venous blood was drawn from the patient's forearm (median cubital vein) (Fig 1A) and were transferred into two plain plastic test tubes (without an anticoagulant) and were centrifuged immediately using a tabletop centrifuge at $700 \mathrm{rpm}$ for 3 minutes $(60 \times \mathrm{g})$ at room temperature ${ }^{(9)}$. The surface liquid layer was collected as the i-PRF. After that, the i-PRF was injected inside the canals using a plastic syringe with a 25 gauge needle (Fig 1B) that was placed $1 \mathrm{~mm}$ short of the working length and was 


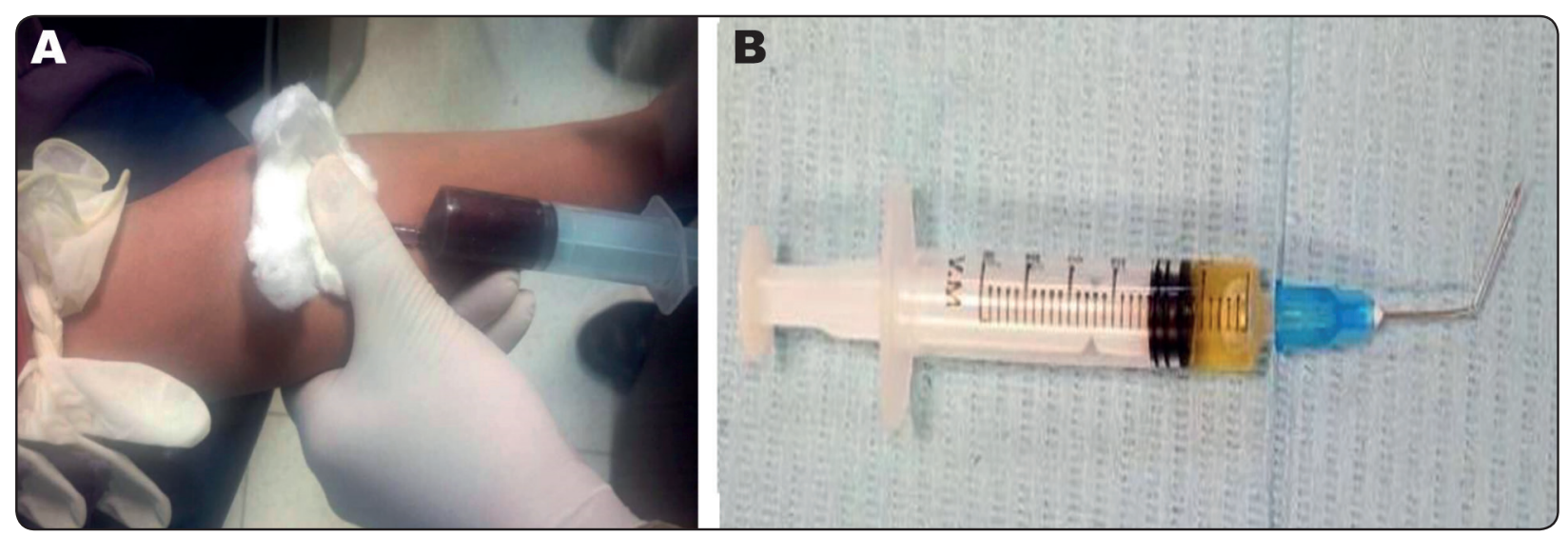

Fig. (1) A: Blood sample collection from the patient. B: Collected iPRF in a plastic syringe ready for intracanal injection.

withdrawn gradually while injecting till reaching the canal orifice. A Collagen membrane matrix (collacote) was placed $1 \mathrm{~mm}$ below the level of the canal orifice and was left for 5 minutes to partially harden then a $3 \mathrm{~mm}$ thick layer of Biodentine was placed directly over the collacote at the level of the canal orifice. The cavity was double sealed with a glass ionomer cement base and a resin composite restoration.

Digital radiographic imaging was performed 3, 6, 9 and 12 months postoperatively using the same $\mathrm{x}$-ray machine. The radiographic parameters were also the same as preoperatively. Visual evaluation of the radiographic images, to monitor the changes in size of the periapical radiolucency through the follow up periods was done. Cone Beam Computed Tomography (CBCT) was performed at 12 months postoperatively using the same preoperative parameters; to assess the bone healing by measuring the size of periapical lesion in $\mathrm{mm}^{2}$ in the sagittal view using the area tool in OnDemand CBCT software.

\section{Statistical analysis}

All the collected data were tabulated and subjected to statistical analysis. Statistical analysis was performed by SPSS in general (version 17). Microsoft office Excel was used for data handling and graphical presentation. Quantitative variables were described by the Mean and Standard Deviation (SD). Qualitative categorical variables were described by proportions and percentages. Kolmogorov-Smirnova and Shapiro-Wilk tests of normality were used to test normality hypothesis of all quantitative variables for further choice of appropriate parametric and non-parametric tests. Paired sample t-test and independent samples t-test were used. General Linear Model Repeated measure ANOVA mixed model design with one between factors and one within factors are applied. The results were considered significant at $\mathrm{P}<0.05$.

\section{RESULTS}

The evaluation of the clinical signs and symptoms showed that there was no pain, swelling or fistula formation throughout the follow up periods. The measurements of periapical lesion perimeter in the control group resulted in a decrease in the mean value, with a highly significant difference between preoperative records and the postoperative and follow-up records (12 months), with a $\mathrm{P}$ value $<0.05$ (Fig 2) (Table 1). The mean measurements of periapical lesion perimeter in the intervention group with the paired t-test resulted in a decrease in the mean value, with a highly significant difference between preoperative records and the postoperative and follow-up records (12 months), a P value $<0.05$ (Fig2) (Table1). 
TABLE (1): Mean value measurements of periapical lesion perimeter at preoperative and postoperative 12 months follow up period in both groups.

\begin{tabular}{|c|c|c|c|}
\hline Group & & Preoperative & 12 months \\
\hline \multirow{5}{*}{ Control } & $\mathbf{N}$ & 15 & 15 \\
\hline & Mean & 39.75 & 17.05 \\
\hline & SD & 16.03 & 8.01 \\
\hline & \multicolumn{2}{|r|}{ t value } & 8.55 \\
\hline & \multicolumn{2}{|r|}{ P value } & $0.00000^{\$}$ \\
\hline \multirow{5}{*}{ Intervention } & $\mathbf{N}$ & 15 & 15 \\
\hline & Mean & 47.69 & 14.12 \\
\hline & SD & 16.14 & 5.00 \\
\hline & \multicolumn{2}{|r|}{ t value } & 10.48 \\
\hline & \multicolumn{2}{|r|}{ P value } & $0.00000^{\$}$ \\
\hline \multicolumn{2}{|l|}{$t$ value } & -1.35 & 1.20 \\
\hline \multicolumn{2}{|l|}{ P value } & $0.18729^{\text {ns }}$ & $0.23936^{\mathrm{ns}}$ \\
\hline
\end{tabular}

$\$=$ significant $\quad n s=$ non significant

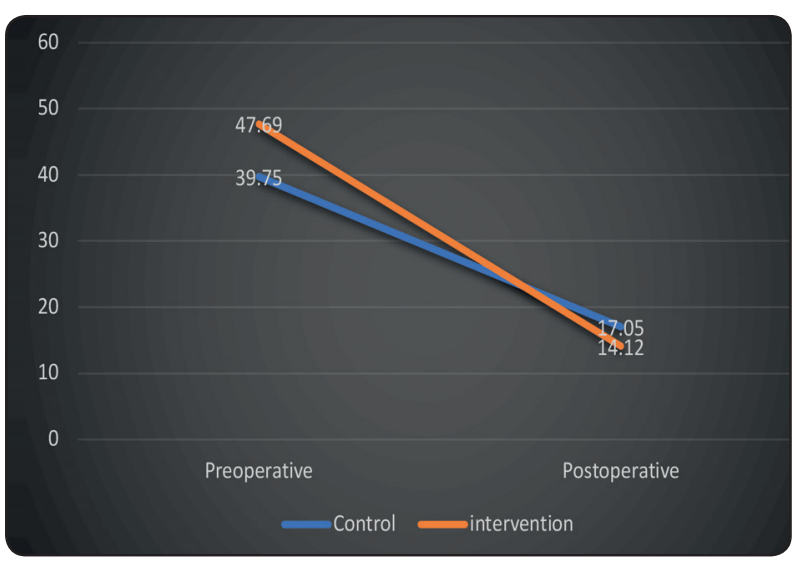

Fig. 2: Line chart representing the mean changes of periapical lesion size with time in each group and comparing both groups with each other.
At the preoperative time, the highest and lowest perimeter of periapical lesion in the control group was $60.32 \mathrm{~mm}^{2}$, and $14.57 \mathrm{~mm}^{2}$, respectively. While the highest and lowest perimeter of periapical lesion in the intervention group was $69.65 \mathrm{~mm}^{2}$, and $18.67 \mathrm{~mm}^{2}$, respectively. The intervention group recorded a higher mean value preoperatively, while it recorded a lower mean value than the control group at 12 months follow up; indicating a decrease in the lesion size. However, the independent t-test showed that the difference was not statistically significant. Comparing the mean measurements of periapical lesion perimeter of both groups; at the preoperative and postoperative measurements, showed a non-significant difference with a $P$ value $>0.05$ (Table 1 ). Comparing the percentage changes of periapical lesion perimeter between both groups using independent $\mathrm{t}$-test revealed that there was a significant difference between the preoperative and 12 months follow up (Table 2).

Sagittal view of CBCT images showed the difference in periapical lesion size between both groups after 12 months follow up period revealing the success of the i- PRF revascularization technique in treatment of necrotic pulp with apical periodontitis in maxillary anterior teeth (Figure 3)

TABLE (2): Comparison of the percentage (\%) change of periapical lesion size at preoperative and postoperative 12 months follow-up period between both groups

\begin{tabular}{|c|c|c|c|c|c|c|}
\hline & Mean & S.D. & Mean difference & $\begin{array}{c}\text { Standard error } \\
\text { of difference }\end{array}$ & t value & P value \\
\hline Control & -56.76 & 13.97 & \multirow{2}{*}{12.44} & 4.43 & 2.8 & $0.01^{\$}$ \\
\hline Intervention & -69.2 & 10.01 & & & \\
\hline
\end{tabular}



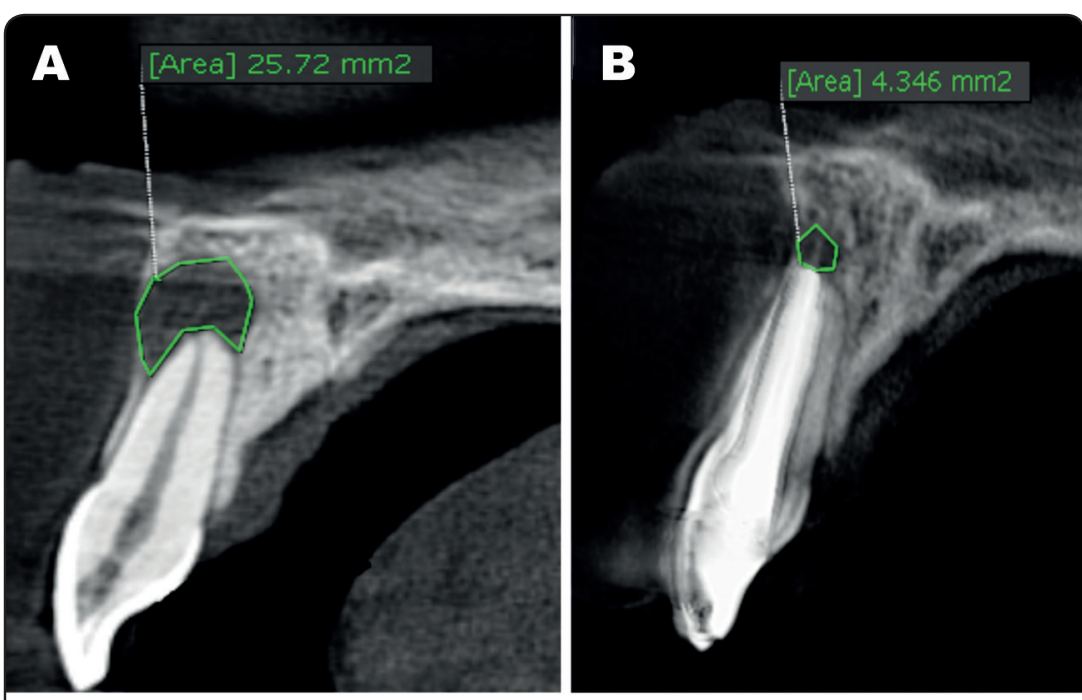

Fig. (3) Sagittal view of CBCT images, A: preoperative periapical lesion size measurement of upper central incisor in control group, B: 12 months Postoperative image showing decrease in periapical lesion size measurement, $\mathrm{C}$ : preoperative periapical lesion size measurement of upper central incisor in i-PRF group, D: 12 months Postoperative periapical lesion size measurement showing complete healing and almost resolution of the lesion.

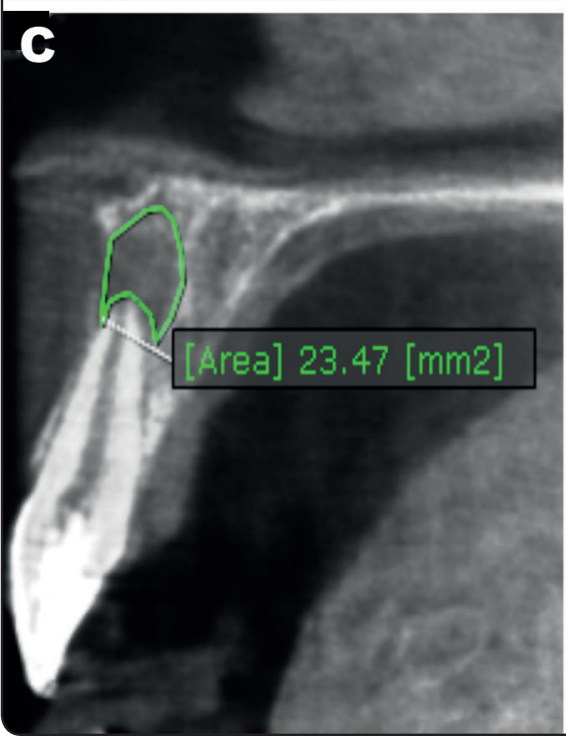

D

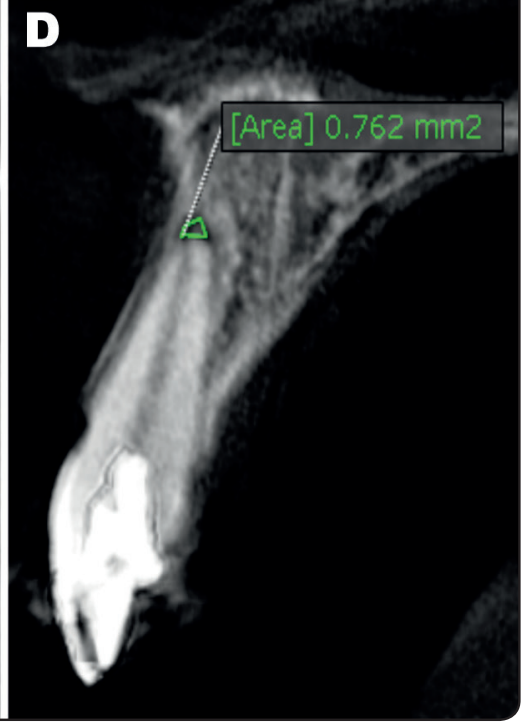

\section{DISCUSSION}

The main goal of root canal therapy is to eliminate microorganisms and infected debris from the root canal system to prevent or treat apical periodontitis. In mature teeth, disinfection is carried out with the integration of mechanical instrumentation, irrigation, and placement of an intracanal medicament, however it may be difficult due to the complexity of the root canal system. In this study a novel treatment regenerative protocol is adopted using iPRF as a scaffold and source if growth factors which aided in complete resolution of signs and symptoms and complete healing of apical periodontitis.
Central incisors were selected in this study owing to their wide canals and larger apical foramina where larger preparations that reached \#60-80 is thought to allow deeper penetration of irrigants and medicaments for disinfection and decreasing the microorganism load and better application of the $\operatorname{iPRF}^{(7,13)}$.

Irrigation of the root canals with $20 \mathrm{~mL} 1.5 \%$ $\mathrm{NaOCl}$ for 5 minutes was done using a closed-end, side-vented needle to minimize the possibility of the extrusion of the irrigant into the periapical tissue. Although using a high concentration of $\mathrm{NaOCl}$ such as $5.25 \%$ would be more tissue solvent and has a more potent antimicrobial efficacy, but it possess 
a proteolytic action on the dentin collagen matrix which might cause a decrease in the elastic modulus and the flexural strength of human dentin and may cause toxicity to stem cells present in the periapical tissues with a decrease in the differentiation potential of odontoblasts ${ }^{(14,15)}$. Calcium hydroxide was used as intracanal medication as it is a good antimicrobial agent due to its high $\mathrm{pH}$ 12.5-12.8, which is not a favorable environment for most bacteria to survive ${ }^{(16-18)}$. Moreover, using calcium hydroxide in regenerative endodontic procedures showed higher survival rate of the apical papilla stem cells ${ }^{(19)}$, and increased the amounts of (TGF)-b1 imprisoned in dentin matrix ${ }^{20} .3 \%$ mepivacaine plain anesthesia was utilized during the second visit to allow the induction of bleeding. EDTA 17\% solution was chosen as a second irrigating solution following $\mathrm{NaOCl}$ as it allows for the release of many growth factors imprisoned in the dentin by its chelating properties ${ }^{21-23)}$. The i-PRF used in the current study was prepared based on the "lowspeed Concept" for blood centrifugation which states that lower centrifugation speeds were shown to include a large amount of cells among which are leukocytes prior to the formation of a fibrin $\operatorname{clot}^{(24)}$. It was shown that i-PRF was able to cause a higher release of growth factors such as TGF- $\beta 1$, PDGF, VEGF, IGF and EGF when compared to the classic PRF and PRP ${ }^{(10)}$, which may be attributed to the high centrifugation forces during the preparation of the PRP or the PRF that is known to shift cell populations from the top of the centrifugation tubes towards the bottom. Since leukocytes are immune cells that have a great value in the tissue regeneration field as they can direct and recruit different types of cells during the wound healing process ${ }^{(25-27)}$, it was thought that reducing the centrifugation G-force might cause a total increase in leukocyte numbers that would be concentrated in the top third layer of the test tubes ${ }^{(10,24)}$.

Biodentine was used to seal the canals orifices owing to its physical qualities and handling properties $^{28}$. Moreover, it has a high push-out bond strength with dentinal walls preventing its dislodgement ${ }^{29}$. Biodentine as all of the tricalcium silicate cements is a bioactive material that is able to form hydroxyapatite crystals at the surface. These crystals is thought to increase the sealing ability, especially when formed at the interface of the material with dentinal walls ${ }^{(30)}$. Biodentine significantly increase TGF-B1 which has a great role in angiogenesis, progenitor cells recruitment, cell differentiation and tissue mineralization ${ }^{(31)}$.

CBCT was used for the assessment of healing owing to the fact that it is the most popular 3D imaging technique that was shown to overcome various limitations of the $2 \mathrm{D}$ periapical radiographs as it is capable of detecting small size lesions, and cancellous bone solely confined lesions which cannot be detected on periapical radiographs. Also, it allows viewing lesions in three dimensions and allows for the measurement of low density areas to give an accurate estimate of the actual lesion size ${ }^{(32)}$.

According to American Association of Endodontists guidelines, all the cases of the i-PRF revascularization technique group were considered successful; where the primary goals of regenerative endodontics were achieved such as the resolution of apical periodontitis and the elimination of clinical signs/symptoms ${ }^{(33,34)}$. Also, there was a decrease in the size of the periapical radiolucencies and an increase in periapical bone densities. Both the periapical lesion size reduction and the increase in periapical bone density were highly significant between the preoperative records and the postoperative follow-up records (12 months) in both the control and the intervention groups. For the control group, our results were in agreement with that of Van Der Borden et al. $2013^{(35)}$ and Fike $2016^{(36)}$ who stated that periapical lesions decreased in size following endodontic treatment which was confirmed by CBCT imaging after 1037 months, and 3-12 months respectively. This may be attributed to the reduction of periapical inflammation by antimicrobial medicaments, and entombing the residual bacteria with obturation. 
Moreover, the results support the finding of Murphy et al. $1991^{(37)}$, as they found that the length of follow-up period was a significant factor and that if this period was extended to 12 months following nonsurgical endodontic treatment, the percentage of the lesions that might demonstrate complete healing would be more than that of 6 months or less follow up periods. Concerning the intervention group in this study; our results showed successful periapical healing and was in coincide with that of Shivashankar et al $2012{ }^{(5)}$, Keswani and Pandey $2013^{(38)}$ and Bakhtiar et al $2017^{(39)}$ who reported complete radiographic periapical healing following revascularization procedures of immature teeth after 12 months using PRF which has nearly the same composition of iPRF used in this study except that the iPRF was proven to release more growth factors, having more leukocyte concentrations and easily applied as mentioned before. In addition, our results support the successful outcome of revascularization of mature teeth in the studies of Saoud et al. $2015^{(40)}$ and Saoud et al $2016^{(41)}$ where there was a resolution of the periapical lesions after 13-14 months, and 8-26 months respectively. A hypothesis for these results might be that if the bacterial load inside the root canal is effectively reduced, the inflammatory periapical lesions might heal even without root canal fillings ${ }^{(43,44)}$

\section{CONCLUSION}

Injectable Platelet rich fibrin (i-PRF) revascularization is a successful regenerative endodontic treatment modality in mature permanent Incisors with closed apex.

\section{REFERENCES}

1. Murray PE, Garcia-Godoy F, Hargreaves KM. Regenerative endodontics: a review of current status and a call for action. J Endod. 2007;33(4):377-390. doi:10.1016/j. joen.2006.09.013

2. Thibodeau B, Trope M. Pulp revascularization of a necrotic infected immature permanent tooth: case report and review of the literature. Pediatr Dent. 2007;29(1):47-50. http://www. ncbi.nlm.nih.gov/pubmed/18041512. Accessed November $22,2016$.

3. Ding RY, Cheung GS pan, Chen J, Yin XZ, Wang QQ, Zhang CF. Pulp Revascularization of Immature Teeth With Apical Periodontitis: A Clinical Study. J Endod. 2009;35(5):745-749. doi:10.1016/j.joen.2009.02.009

4. Trope M. Treatment of the Immature Tooth with a NonVital Pulp and Apical Periodontitis. Dent Clin North Am. 2010;54(2):313-324. doi:10.1016/j.cden.2009.12.006

5. Shivashankar VY, Johns DA, Vidyanath S, Kumar MR. Platelet Rich Fibrin in the revitalization of tooth with necrotic pulp and open apex. J Conserv Dent. 2012;15(4):395-398. doi:10.4103/0972-0707.101926

6. Sachdeva G, Sachdeva L, Goel M, Bala S. Regenerative Endodontic Treatment of an Immature Tooth With a Necrotic Pulp and Apical Periodontitis Using PlateletRich Plasma (PRP) and Mineral Trioxide Aggregate (MTA): A Case Report. Int Endod J. 2015;48(9):902-910. doi:10.1111/IEJ.12407

7. Nageh M, Ahmed GM, El-Baz AA. Assessment of Regaining Pulp Sensibility in Mature Necrotic Teeth Using a Modified Revascularization Technique with Platelet-rich Fibrin: A Clinical Study. J Endod. 2018;44(10):1526-1533. doi:10.1016/j.joen.2018.06.014

8. Abou Samra RA, El Backly RM, Aly HM, Nouh SR, Moussa SM. Revascularization In Mature Permanent Teeth With Necrotic Pulp And Apical Periodontitis: Case Series. Alexandria Dent J. 2018;43(2):7-12. doi:10.21608/ adjalexu.2018.57617

9. Miron RJ, Fujioka-kobayashi M, Hernandez M. Injectable platelet rich fibrin ( $\mathrm{i}-\mathrm{PRF}$ ): opportunities in regenerative dentistry? Clin Oral Investig. 2017;21(8):2619-2627. doi:10.1007/s00784-017-2063-9

10. Varela HA, Souza JCM, Nascimento RM, et al. Injectable platelet rich fibrin: cell content, morphological, and protein characterization. Clin Oral Investig. 2019;23(3):13091318. doi: $10.1007 / \mathrm{s} 00784-018-2555-2$

11. Lee B-N, Moon J-W, Chang H-S, Hwang I-N, Oh W-M, Hwang Y-C. A review of the regenerative endodontic treatment procedure. Restor Dent Endod. 2015;40(3):179. doi:10.5395/rde.2015.40.3.179

12. AAE- American Association Of Endodontics-Regenerative Endodontics, 2016. http://www.aae.org/regeneration/. Published 2016. 
13. Card SJ, Sigurdsson A, Orstavik D, Trope M. The effectiveness of increased apical enlargement in reducing intracanal bacteria. J Endod. 2002;28(18):779-783. doi:10.1097/00004770-200211000-00008

14. Sim TPC, Knowles JC, Ng YL, Shelton J, Gulabivala K. Effect of sodium hypochlorite on mechanical properties of dentine and tooth surface strain. Int Endod J. 2001;34(2):120132. doi:10.1046/j.1365-2591.2001.00357.x

15. Trevino EG, Patwardhan AN, Henry MA, et al. Effect of irrigants on the survival of human stem cells of the apical papilla in a platelet-rich plasma scaffold in human root tips. J Endod. 2011;37(8):1109-1115. doi:10.1016/j. joen.2011.05.013

16. SJögren U, Figdor D, Spanberg L, Sundqvist G. The antimicrobial effect of calcium hydroxide as a short-term intracanal dressing. Int Endod J. 1991;24(3):119-125. doi:10.1111/j.1365-2591.1991.tb00117.x

17. Estrela C, Sydney GB, Bammann LL FJO. Mechanism of action of calcium and hydroxyl ions of calcium hydroxide on tissue and bacteria. Braz Dent J. 1995;6(2):85-90.

18. Mohammadi Z, Dummer P. Properties and Applications of Calcium Hydroxide in Endodontics and Dental Traumatology. Int Endod J. 2011;44(8):697-730. doi:10.1111/J.13652591.2011.01886.X

19. Kitikuson P, Srisuwan T. Attachment Ability of $\mathrm{Hu}-$ man Apical Papilla Cells to Root Dentin Surfaces Treated with Either 3Mix or Calcium Hydroxide. J Endod. 2016;42(1):89-94. doi:10.1016/j.joen.2015.08.021

20. Galler KM, D'Souza RN, Federlin M, et al. Dentin conditioning codetermines cell fate in regenerative endodontics. J Endod. 2011;37(11):1536-1541. doi:10.1016/j.joen.2011.08.027

21. Smith AJ, Leaver AG. Distribution of the EDTA-soluble non-collagenous organic matrix components of rabbit incisor dentine. Arch Oral Biol. 1981;26(8):643-649. http:// www.ncbi.nlm.nih.gov/pubmed/6797393. Accessed December 10, 2016.

22. Roberts-Clark DJ, Smith AJ. Angiogenic growth factors in human dentine matrix. Arch Oral Biol. 2000;45(11):10131016. http://www.ncbi.nlm.nih.gov/pubmed/11000388. Accessed December 10, 2016.

23. Almushayt a, Narayanan K, Zaki a E, George A. Dentin matrix protein 1 induces cytodifferentiation of dental pulp stem cells into odontoblasts. Gene Ther. 2006;13(7):611620. doi:10.1038/sj.gt.3302687
24. Ghanaati S, Booms P, Orlowska A, et al. Advanced PlateletRich Fibrin: A New Concept for Cell-Based Tissue Engineering by Means of Inflammatory Cells. J Oral Implantol. 2014;40(6):679-689. doi:10.1563/aaid-joi-D-14-00138

25. B B, EJ C, CA O. Leukocyte Proteinases in Wound Healing: Roles in Physiologic and Pathologic Processes. Wound Repair Regen. 1999;7(6):410-422. doi:10.1046/J.1524475X.1999.00410.X

26. P M. Wound Healing--Aiming for Perfect Skin Regeneration. Science. 1997;276(5309):75-81. doi:10.1126/SCIENCE.276.5309.75

27. T B, DM DE, PA E, A W. The Role of Leukocytes From LPRP/L-PRF in Wound Healing and Immune Defense: New Perspectives. Curr Pharm Biotechnol. 2012;13(7):11531162. doi:10.2174/138920112800624373

28. Malkondu Ö, Kazandağ MK, Kazazoğlu E. A Review on Biodentine, a Contemporary Dentine Replacement and Repair Material. Biomed Res Int. 2014;2014:1-10. doi:10.1155/2014/160951

29. V A, M S, S M, S K. Comparative Evaluation of Push-Out Bond Strength of ProRoot MTA, Biodentine, and MTA Plus in Furcation Perforation Repair. J Conserv Dent. 2013;16(5):462-465. doi:10.4103/0972-0707.117504

30. Koubi S, Elmerini H, Koubi G, Tassery H, Camps J. Quantitative Evaluation by Glucose Diffusion of Microleakage in Aged Calcium Silicate-Based Open-Sandwich Restorations. Int J Dent. 2012;2012:1-6. doi:10.1155/2012/105863

31. P L, J C, I A. Biodentine(TM) Induces TGF- $\beta 1$ Release From Human Pulp Cells and Early Dental Pulp Mineralization. Int Endod J. 2012;45(5):439-448. doi:10.1111/ J.1365-2591.2011.01995.X

32. Ahlowalia MS, Patel S, Anwar HMS, et al. Accuracy of CBCT for volumetric measurement of simulated periapical lesions. Int Endod J. 2013;46(6):538-546. doi:10.1111/ iej. 12023

33. Bose R, Nummikoski P, Hargreaves K. A Retrospective Evaluation of Radiographic Outcomes in Immature Teeth With Necrotic Root Canal Systems Treated With Regenerative Endodontic Procedures. J Endod. 2009;35(10):13431349. doi:10.1016/j.joen.2009.06.021

34. Hargreaves KM, Diogenes A, Teixeira FB. Paradigm lost: A perspective on the design and interpretation of regenerative endodontic research. J Endod. 2014;40(4 SUPPL.):S65-S69. doi:10.1016/j.joen.2014.01.023 
35. Van Der Borden WG, Wang X, Wu MK, Shemesh H. Area and 3-dimensional volumetric changes of periapical lesions after root canal treatments. J Endod. 2013;39(10):12451249. doi:10.1016/j.joen.2013.07.001

36. Fike J. Assessment of changes in the size of periapical radiolucencies 3-12 months post non-surgical root canal treatment using CBCT imaging: A pilot study. Theses Diss. 2016;Virginia C:1-92. https://scholarscompass.vcu.edu/ etd/4139. Accessed September 15, 2018.

37. Murphy WK, Kaugars GE, Collett WK, Dodds RN. Healing of periapical radiolucencies after nonsurgical endodontic therapy. Oral Surgery, Oral Med Oral Pathol. 1991;71(5):620-624. doi:10.1016/0030-4220(91)90374-L

38. Keswani D, Pandey RK. Revascularization of an immature tooth with a necrotic pulp using platelet-rich fibrin: a case report. Int Endod J. 2013;46(11):1096-1104. doi:10.1111/ iej.12107

39. Bakhtiar H, Esmaeili S, Fakhr Tabatabayi S, Ellini MR, Nekoofar MH, Dummer PMH. Second-generation Platelet Concentrate (Platelet-rich Fibrin) as a Scaffold in Regenerative Endodontics: A Case Series. J Endod. 2017;43(3):401-408. doi:10.1016/j.joen.2016.10.016
40. Saoud TMA, Huang GTJ, Gibbs JL, Sigurdsson A, Lin LM. Management of teeth with persistent apical periodontitis after root canal treatment using regenerative endodontic therapy. J Endod. 2015;41(10):1743-1748. doi:10.1016/j. joen.2015.07.004

41. Saoud TM, Martin G, Chen Y-HM, et al. Treatment of Mature Permanent Teeth with Necrotic Pulps and Apical Periodontitis Using Regenerative Endodontic Procedures: A Case Series. J Endod. 2016;42(1):57-65. doi:10.1016/j. joen.2015.09.015

42. Saoud TMA, Sigurdsson A, Rosenberg PA, Lin LM, Ricucci D. Treatment of a large cystlike inflammatory periapical lesion associated with mature necrotic teeth using regenerative endodontic therapy. J Endod. 2014;40(12):2081-2086. doi:10.1016/j.joen.2014.07.027

43. Klevant FJH, Eggink CO. The effect of canal preparation on periapical disease. Int Endod J. 1983;16(2):68-75. doi:10.1111/j.1365-2591.1983.tb01299.x

44. Sabeti MA, Nekofar M, Motahhary P, Ghandi M, Simon JH. Healing of apical periodontitis after endodontic treatment with and without obturation in dogs. J Endod. 2006;32(7):628-633. doi:10.1016/j.joen.2005.12.014 